Revista Agrotecnologia, Anápolis, GO

http://www.revista.ueg.br/index.php/agrotecnologia

Recebido: 22/05/2015 - Aprovado 30/07/2015

\title{
PRODUÇÃO DE ALFACE AMERICANA EM FUNÇÃO DA ÉPOCA DE CULTIVO E DOSES DE NITROGÊNIO
}

Jony Eishi Yuri ${ }^{1}$, Geraldo Milanez de Resende ${ }^{1}$, José Hortêncio Mota ${ }^{2}$, Rovilson José de Souza $^{3}$, Lauro Luiz Petrazzini ${ }^{4}$

Resumo: Este estudo teve por objetivo avaliar a resposta da alface americana cultivada em diferentes épocas do ano à doses de nitrogênio em adubação de cobertura. O experimento foi realizado em blocos casualizados, com quatro repetições, em esquema fatorial $2 \times 4$, sendo o primeiro fator constituído pelas épocas de cultivo (verão e inverno) e o segundo pelas quatro doses de nitrogênio $\left(30,90,150\right.$ e $\left.180 \mathrm{~kg} \mathrm{ha}^{-1}\right)$. Como fonte de nitrogênio utilizou-se a ureia (45\% de N) aplicada via fertirrigação. Para a característica massa fresca total verificou-se efeito significativo para época de cultivo e doses de nitrogênio. Para o cultivo de verão, os resultados mostraram que, a soma entre a adubação de base $\left(30 \mathrm{~kg} \mathrm{ha}^{-1}\right)$ e a menor dose aplicada via fertirrigação $\left(30 \mathrm{~kg} \mathrm{ha}^{-1}\right)$, proporcionou melhor resposta, com rendimento de $665,9 \mathrm{~g}$ planta $^{-1}$. Já para o cultivo no inverno, o maior rendimento foi obtido com a dose total de $125 \mathrm{~kg} \mathrm{ha}^{-1}$ de N.Para massa fresca comercial verificou-se efeito significativo para o fator época de cultivo. Resultados semelhantes foram observados na circunferência de cabeça e no comprimento de caule. Para a qualidade pós-colheita, observou-se efeito significativo entre os tratamentos apenas aos 21 dias de armazenamento.

PALAVRAS-CHAVE: Lactuca sativa L. Macronutriente. Verão. Inverno. Adubação de cobertura.

\section{NITROGEN RATES AND SEASONS OF CULTIVATION OF CRISPHEAD LETTUCE}

\footnotetext{
${ }^{1}$ Pesquisador Doutor da Embrapa Semi-Árido, Caixa Postal 23, CEP 56.302-970, Petrolina-PE, Brasil. E-mail. jony.yuri@embrapa.br

${ }^{2}$ Professor Doutor da Universidade Federal de Goiás - Regional Jataí, BR 364, km 193, CEP: 75.801-615, JataíGO, Brasil.

${ }^{3}$ Professor Doutor da Universidade Federal de Lavras, Cx. Postal 3037, CEP 37.200-000, Lavras-MG, Brasil.

${ }^{4}$ Professor Doutor da Universidade de Cuiabá - Campus Primavera do Leste, Av. Paulo César Aranda, 241, Jardim Riva, CEP 78.850-000, Primavera do Leste-MT, Brasil.
} 
Abstract: The present study aimed to evaluate nitrogen rates in topdressing in crisphead lettuce cultivated in different seasons of the year. The experimental design was a randomized complete block design with four replications in a $2 \times 4$ factorial, with the first factor consists of the growing seasons (summer and winter) and the second of four nitrogen levels $(30,90$, 150 and $\left.180 \mathrm{~kg} \mathrm{ha}^{-1}\right)$ in topdressing. Urea (45\% of $\mathrm{N}$ ) was the nitrogen source and the application was by fertirrigation. For total fresh mass showed significant effect to growing season and nitrogen rates. For summer cultivation, the results showed that the sum between fertilization of foundation, that in this case it was used $30 \mathrm{~kg} \mathrm{ha}^{-1}$ of $\mathrm{N}$, and the lowest dose by fertirrigation $\left(30 \mathrm{~kg} \mathrm{ha}^{-1}\right.$ ), provided better result. In this dose, it was obtained $665.9 \mathrm{~g} \mathrm{plant}^{-1}$. Already, when the growing season occurred in winter, the highest yield was obtained with a total dose of $125 \mathrm{~kg} \mathrm{ha}^{-1} \mathrm{~N}$. The commercial fresh mass showed as result, only significant effect for cultivation season factor. Similar results were observed in the circumference of the head and stem length. For the postharvest quality, there was a significant effect among treatments, only after 21 days of storage.

KEY-WORDS: Lactuca sativa L. Macronutrient. Summer. Winter. Topdressing.

\section{INTRODUÇÃO}

Inicialmente voltado para abastecer uma grande rede de lanchonetes, atualmente, o cultivo de alface-americana no sul de Minas Gerias tem se destacado no cenário da produção de hortaliças folhosas no país em razão de uma série de fatores, entre as quais: abundância de áreas propícias para o cultivo; abundância de água para a irrigação; equidistância dos três principais centros consumidores (São Paulo, Rio de Janeiro e Belo Horizonte); presença de mão de obra, etc.

Trata-se de um tipo de alface que apresenta o formato imbricado, semelhante a um repolho, com folhas externas escuras e internas mais claras ou amareladas. Apresenta uma textura mais crocante, muito indicado para ser utilizado em lanches (YURI et al., 2006). A alfaceamericana tem como característica principal, sua grande capacidade de conservação pós-colheita e tolerância ao transporte a longas distâncias (DECOTEAU et al., 1995). Entretanto, essa característica pode ser afetada por alguns fatores tais como, condições climáticas, época de cultivo, cultivares e condições nutricionais das plantas.

Embora seja reconhecida como planta típica de clima temperado, a alface possui cultivares melhoradas 
geneticamente com maior tolerância às temperaturas elevadas, o que possibilita seu cultivo todo o ano; no entanto, existem dois períodos climáticos pouco favoráveis ao seu cultivo: o verão e o inverno (FELTRIM et al., 2005)

Para alface americana, a temperatura ideal para o desenvolvimento o desenvolvimento está na faixa de 15,5 a 28,3 ${ }^{\circ} \mathrm{C}$ (ARAÚJO et al., 2010), sendo que temperaturas muito elevadas podem provocar distúrbios fisiológicos (SOUZA et al., 2013) e também contribuir para ocorrer deficiência de cálcio, conhecido como "tip-burn".

Pelo fato de a cultura ser composta basicamente de folhas, a mesma responde bem ao fornecimento de nitrogênio, nutriente que requer um manejo especial quanto à adubação, por ser de fácil lixiviação e pelo fato da alface absorver maior quantidade na fase final do ciclo (RESENDE et al., 2012).

O nitrogênio é um macronutriente encontrado em compostos orgânicos como aminoácidos e ácidos nucleicos. Participa de diversos processos fisiológicos vitais para o ciclo de vida das plantas - absorção iônica, fotossíntese, respiração, multiplicação e diferenciação celulares e herança. Esse nutriente, quando absorvido pelas raízes, é transportado via corrente transpiratória para a parte aérea da planta através dos vasos do xilema, sendo facilmente redistribuído via floema, na forma de aminoácidos. Assim, na falta de nitrogênio, ocorre uma mobilização do $\mathrm{N}$ das folhas velhas para órgãos e folhas mais novas. Consequentemente, em plantas deficientes, os sintomas surgem primeiramente nas folhas velhas (EPSTEIN; BLOOM, 2004).

O que se observa no Brasil é a necessidade de maiores pesquisas sobre doses de fertilizantes a serem utilizadas, adequadas às diferentes cultivares, regiões e épocas de plantio, que desmotivem o olericultor a realizar testes em sua propriedade ou simplesmente a adotar recomendações de firmas revendedoras de fertilizantes. Além disto, na ansiedade de obter maior produtividade, o olericultor aplica em excesso, elementos minerais, resultando muitas vezes em distúrbios nutricionais nas plantas, além de acarretar aumento do custo de produtividade (RESENDE et al., 2005).

Dessa forma, diante da variabilidade de estudos comnitrogênio, Bastos et al. (2008) destacam que pesquisasregionais visando determinar as doses econômicas denitrogênio são de grande importância para que o agricultorpossa racionalizar os custos de produção e aumentar arentabilidade da cultura.

Diante do exposto, com o presente trabalho objetivou-se a avaliar doses de nitrogênio em adubação de cobertura para 
a cultura de alface-americana cultivada em diferentes épocas do ano, nas condições do

\section{MATERIAL E MÉTODOS}

O experimento foi realizado no município de Três Pontas, Sul de Minas Gerais, a uma altitude de $870 \mathrm{~m}$, situada a $21^{\circ} 22^{\prime} 00^{\prime \prime}$ de longitude sul e $45^{\circ} 30^{\prime} 45^{\prime \prime}$ de longitude oeste. O clima da região é caracterizado por temperatura média anual variando de $15,8^{\circ} \mathrm{C}$ no mês mais frio, a $22,1^{\circ} \mathrm{C}$ no mês mais quente; a precipitação média anual é de $1.529,7 \mathrm{~mm}$ e a umidade relativa do ar é de $76,2 \%$.

O solo predominante na área é classificado como Latossolo Vermelho distroférrico de textura argilosa (EMBRAPA, 2013), apresentando as características químicas: $\mathrm{pH}$ em $\mathrm{H}_{2} \mathrm{O}$ (1:2,5) - 6,0; matéria orgânica - $24 \mathrm{~g} \mathrm{~kg}^{-1}$ : $\mathrm{P}$ - 78,0,0 mg dm${ }^{-3}: \mathrm{K}-73,0 \mathrm{mg} \mathrm{dm}^{-3} ; \mathrm{Ca}-$ $4,3{ }_{\mathrm{c}}$ molc dm ${ }^{-3} ; \mathrm{Mg}-0,8{ }_{\mathrm{c}}$ molc dm ${ }^{-3} ; \mathrm{Al}-$ $0,0{ }_{\mathrm{cmolc} \mathrm{dm}^{-3}}$; Fe - 25,0 $\mathrm{mg} \mathrm{dm}^{-3} ; \mathrm{Mn} \mathrm{-}$ $14,2 \mathrm{mg} \mathrm{dm}^{-3} ; \mathrm{Cu}-1,0 \mathrm{mg} \mathrm{dm}^{-3} ; \mathrm{B}-0,3$ $\mathrm{mg} \mathrm{dm}{ }^{-3} ; \mathrm{Zn}-0,8 \mathrm{mg} \mathrm{dm}^{-3}$.

O delineamento experimental utilizado foi de blocos casualizados, com quatro repetições, em esquema fatorial $2 \mathrm{x}$ 4, sendo o primeiro fator constituído pelas épocas de cultivo (verão, com semeadura no mês de dezembro e inverno com semeadura no mês de maio) e o segundo pelas quatro doses de nitrogênio $(30,0$; município de Três Pontas-MG.

90,0; 150,0 e 180,0 $\left.\mathrm{kg} \mathrm{ha}^{-1}\right)$.A cultivar utilizada foi Raider. Como fonte de nitrogênio utilizou-se a ureia $(45 \%$ de $\mathrm{N})$, sendo a aplicação realizada via fertirrigação.

As parcelas experimentais constituíram- se de canteiros com quatro linhas de 2,1 m de comprimento, com espaçamento entre linhas de $0,30 \mathrm{~m}$ e entre plantas de 0,35 m. As linhas centrais formaram a área útil, desprezando-se as duas plantas de cada extremidade. Os canteiros foram revestidos com filme plástico preto "mulching", de 1,6 $\mathrm{m}$ de largura e 35 micrômetros de espessura.

$\mathrm{Na}$ adubação de plantio utilizou-se $30 \mathrm{~kg} \mathrm{ha}^{-1}$ de $\mathrm{N}, 600 \mathrm{~kg} \mathrm{ha}^{-1}$ de $\mathrm{P}_{2} \mathrm{O}_{5}$ e 120 $\mathrm{kg} \mathrm{ha}^{-1}$ de $\mathrm{K}_{2} \mathrm{O}$, sendo as fontes o adubo formulado $02-18-08$ e o superfosfato simples. Essa mistura foi incorporada ao solo com enxada rotativa na camada de 0,0-0,2 m. As adubações de cobertura foram realizadas por meio de fertirrigações, que se iniciaram cinco dias após o transplanto e se estenderam até o momento da colheita, três vezes por semana. As doses de nitrogênio foram aplicadas conforme os tratamentos e o potássio, fixado em uma dose de $120,0 \mathrm{~kg}$ $\mathrm{ha}^{-1}$ de $\mathrm{K}_{2} \mathrm{O}$. A fonte de potássio utilizada foi o $\mathrm{KCl}$. 
O transplantio das mudas, formadas em bandejas multicelulares de 200 células cada uma, preenchidas com substrato comercial $\left(\right.$ Plantmax $^{\circledR}$ ), foi realizado aos 26 e 31 dias após a semeadura, respectivamente, para o primeiro $\mathrm{e}$ segundo cultivo. As irrigações foram diárias e os demais tratos culturais foram os comuns aos praticados para a cultura na região.

As colheitas foram realizadas aos 44 e 60 dias após o transplantio no verão e no inverno, respectivamente. Logo após a colheita realizou-se as avaliações da massa fresca total e comercial (g planta ${ }^{-1}$ ); circunferência da cabeça comercial $(\mathrm{cm})$ e comprimento do caule $(\mathrm{cm})$. A massa fresca total $\left(\mathrm{g}_{\text {planta }}{ }^{-1}\right)$ foi obtida cortando as plantas bem rente ao solo e pesando em balança modelo US.15/5 da marca Urano, com sensibilidade de $5 \mathrm{~g}$. A massa fresca comercial $\left(\mathrm{g} \mathrm{planta}^{-1}\right)$, foi obtida pesando somente as "cabeças" comerciais, retirando-se as folhas externas. Posteriormente, com o auxílio de uma fita métrica, mediou-se a circunferência da cabeça comercial $(\mathrm{cm})$. Ainda, cortou-se a cabeça da alface ao meio, possibilitando a medição do comprimento do caule $(\mathrm{cm})$ com o auxílio de uma régua graduada.

Para as avaliações da conservação pós-colheita foram recolhidas cinco plantas (somente cabeças comerciais, que foram acondicionadas em sacos plásticos) por tratamento e, em seguida, depositadas em câmara frigorífica a $5 \pm 2{ }^{\circ} \mathrm{C}$.Foram realizadas duas avaliações, aos 14 e 21 dias. Adotou-se, conforme Resende et al. (2005), uma escala de notas,sendo utilizada a média das notas atribuídas por três avaliadores: nota 1 - cabeças comerciais extremamente deterioradas; nota 2 cabeças comerciais deterioradas; nota 3 cabeças comerciais moderadamente deterioradas; nota 4 - cabeças comerciais levemente deterioradas e nota 5 - cabeças comerciais sem deterioração.

Os dados foram submetidos à análise de variância $(\alpha=0,05)$, sendo as médias comparadas pelo teste de Tukey para época de cultivo e análise de regressão para doses de nitrogênio.

\section{RESULTADOS E DISCUSSÃO}

Observa-se pelo resumo da análise de variância (Tabela 1) que para a característica massa fresca total ocorreu efeito significativo para época de cultivo e doses de nitrogênio, de forma independente, assim como, para a interação entre os dois fatores. $\mathrm{Na}$ análise dos resultados do desdobramento de doses de nitrogênio dentro de cada época de cultivo, pode-se observar que, nas condições de verão, não houve efeito significativo entre 
YURI, J. E. et al.

as diferentes doses de $\mathrm{N}$ aplicados em fertirrigação.

Tabela 1. Resumo das análises de variância com os níveis de significância das variáveis Massa fresca total (MFT) e comercial (MFC), circunferência de cabeça (CC), comprimento de caule (COM) e qualidade pós-colheita (QPC) de alface americana em função de doses de nitrogênio e época de cultivo.

\begin{tabular}{|c|c|c|c|c|c|c|c|}
\hline \multirow{2}{*}{$\begin{array}{l}\text { Causas de } \\
\text { Variação }\end{array}$} & \multirow[b]{2}{*}{ GL } & \multicolumn{6}{|c|}{ Quadrados Médios } \\
\hline & & MFT & MFC & $\mathrm{CC}$ & $\mathrm{COM}$ & $\begin{array}{c}\text { QPC } \\
14 \text { dias }\end{array}$ & $\begin{array}{l}\text { QPC } \\
21 \text { dias }\end{array}$ \\
\hline Blocos & 2 & 5657,17 & 8016,29 & 3,50 & 0,56 & 0,13 & 0,17 \\
\hline Época & 1 & $110.081,67^{*}$ & $378.508,12 *$ & $183,71 *$ & $24,81^{*}$ & $0,07^{\mathrm{ns}}$ & $0,12^{\text {ns }}$ \\
\hline Doses & 3 & $19250,78^{*}$ & $6240,28^{\mathrm{ns}}$ & $3,84^{*}$ & $0,08^{\mathrm{ns}}$ & $0,17^{\mathrm{ns}}$ & $1,71^{*}$ \\
\hline Épocax Dose & 3 & $8504,33^{\text {ns }}$ & $8483,83^{\text {ns }}$ & $1,60^{*}$ & $0,04^{\mathrm{ns}}$ & $0,33^{\mathrm{ns}}$ & $0,25^{\mathrm{ns}}$ \\
\hline Erro & 14 & 2786,78 & 4023,48 & 0,34 & 0,51 & 0,27 & 0,29 \\
\hline $\mathrm{CV}(\%)$ & & 6,35 & 14,2 & 4,8 & 22,4 & 12,2 & 19,7 \\
\hline
\end{tabular}

Em que: $\mathrm{ns}=$ não significativo; * significativo a 5\% de probabilidade pelo Teste $\mathrm{F}$.

Para essa época de cultivo, os resultados mostraram que, a soma entre a adubação de base, que foi de $30 \mathrm{~kg} \mathrm{ha}^{-1}$, e a menor dose aplicada via fertirrigação $\left(30 \mathrm{~kg} \mathrm{ha}{ }^{-1}\right.$ ) totalizando $60 \mathrm{~kg} \mathrm{ha} \mathrm{ha}^{-1}$, proporciona a maior economia de fertilizante, sem afetar o rendimento. Nesta dose, obteve-se o rendimento de 665,9 g planta $^{-1}$. Esse resultado é semelhante ao observado por Mantovani et al. (2005), que em trabalho de avaliação de doses de nitrogênio em diferentes tipos de alface, nas condições de Jaboticabal-SP, obtiveram para as alfaces do tipo americana, as melhores respostas quando aplicaram um total de $60 \mathrm{~kg} \mathrm{ha}^{-1}$ de $\mathrm{N}$.
Quando a época de cultivo se deu no inverno, foi verificada a significância entre os tratamentos. $\mathrm{Na}$ derivação da equação de regressão para o fator doses, constatouse que a aplicação de $95 \mathrm{~kg} \mathrm{ha}^{-1}$ de $\mathrm{N}$, proporcionou o maior rendimento, que foi de $1.125 \mathrm{~g} \mathrm{planta}^{-1}$ (Figura 1). Se, do mesmo modo, somarmos os $30 \mathrm{~kg} \mathrm{ha}^{-1} \mathrm{de}$ $\mathrm{N}$ adicionados na adubação de base a esse valor obtido, resultando assim, em um total de $125 \mathrm{~kg} \mathrm{ha}^{-1}$ de $\mathrm{N}$, chega-se ao valor considerado como adequado, de acordo com as recomendações de Trani e Raij (1997). 


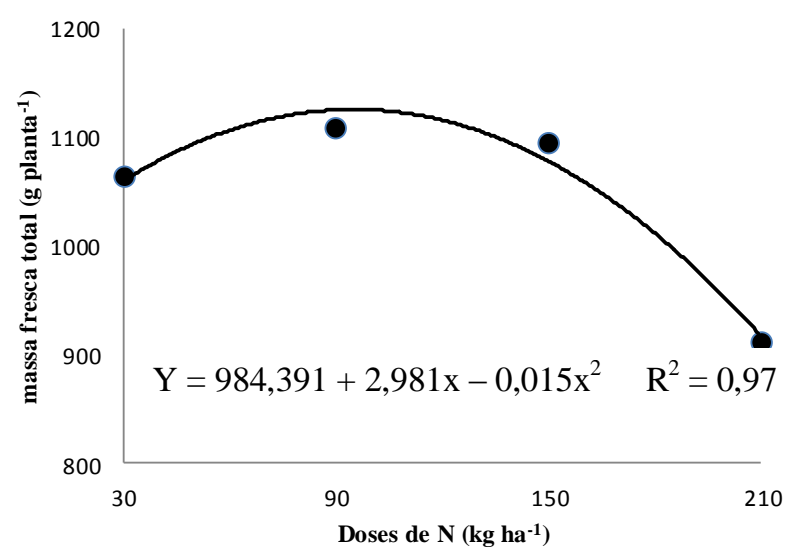

Figura 1. Massa fresca total de alface americana cultivada em condições de inverno em função de doses de nitrogênio.

A análise de variância da massa fresca comercial mostrou como resultado, apenas efeito significativo para o fator época de cultivo. Pelo teste de média realizado chegou-se ao resultado de que nas condições de cultivo de inverno, as plantas de alface-americana apresentaram

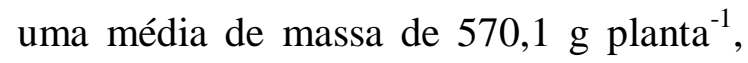
sendo estatisticamente superior ao cultivo de verão, em que a média observada foi de 319,0 g planta $^{-1}$ (Tabela 2).

Tabela 2. Massa fresca total (MFT) e comercial (MFC), circunferência de cabeça (CC), comprimento de caule (COM) e qualidade pós-colheita (QPC) de alface americana em função de doses de nitrogênio e época de cultivo

\begin{tabular}{|c|c|c|c|c|c|c|}
\hline \multirow{2}{*}{ Época } & MFT & $\overline{\mathrm{MFC}}$ & \multirow{2}{*}{$\begin{array}{l}\mathrm{CC} \\
(\mathrm{cm})\end{array}$} & \multirow{2}{*}{$\begin{array}{l}\text { COM } \\
(\mathrm{cm})\end{array}$} & \multirow{2}{*}{$\begin{array}{c}\text { QPC } \\
14 \text { dias }\end{array}$} & \multirow{2}{*}{$\begin{array}{c}\text { QPC } \\
21 \text { dias }\end{array}$} \\
\hline & \multicolumn{2}{|c|}{$\left(\right.$ g planta $\left.^{-1}\right)$} & & & & \\
\hline Inverno & $1.045,50 \mathrm{a}$ & $570,16 a$ & $41,91 \mathrm{a}$ & $4,19 \mathrm{a}$ & $4,25 \mathrm{a}$ & $2,70 \mathrm{a}$ \\
\hline Verão & $617,15 \mathrm{~b}$ & $319,00 \mathrm{~b}$ & $36,38 \mathrm{~b}$ & $2,15 \mathrm{~b}$ & $4,25 \mathrm{a}$ & $2,70 \mathrm{a}$ \\
\hline C. V. (\%) & 6,3 & 14,2 & 4,7 & 22,4 & 12,1 & 19,7 \\
\hline Média & 831,33 & 444,58 & 39,15 & 3,17 & 4,25 & 2,70 \\
\hline
\end{tabular}

De modo semelhante, a circunferência de cabeça e o comprimento de caule apresentaram, nos resultados da análise, efeitos significativos apenas para o fator época de cultivo. Para a primeira característica, foi constatado, nos resultados do teste de média, uma maior circunferência, que foi de $41,9 \mathrm{~cm}$, quando se cultivou nas condições de inverno, enquanto que no verão, a média foi de 36,3 $\mathrm{cm}$, sendo estatisticamente inferior. $\mathrm{O}$ comprimento de caule foi menor nas 
condições de inverno. As plantas apresentaram uma média de $2,15 \mathrm{~cm}$ de caule nessa época e $4,19 \mathrm{~cm}$ no verão (Tabela 1).Essas duas características são importantes para a cultura da alfaceamericana, principalmente, quando o destino da produção for voltado para o processamento. Plantas que apresentam reduzida circunferência de cabeça proporcionam menor rendimento no momento do processamento, pois dificultam o manuseio e, assim, diminuem a velocidade da operação.

Quanto ao caule, este deve ser bastante reduzido, proporcionando menor perda durante o processamento. Além disso, plantas com caule excessivamente comprido não apresentam adequada compacidade e dificulta o beneficiamento, afetando a qualidade final do produto (YURI et al., 2002). Todavia, mesmo nas condições de verão, o comprimento médio observado está dentro de um patamar considerado aceitável, pois, na prática, caule de até $6 \mathrm{~cm}$ tem sido considerado como adequado (RESENDE et al., 2005).

Quanto à qualidade pós-colheita, Bernardi et al. (2005) salientam que a aparência externa das hortaliças é de grande importância, uma vez que o consumidor somente adquire o produto mais atrativo, sendo que análise sensorial pode ser uma ferramenta adequada para avaliar a qualidade ou aparência externa das hortaliças. Para este parâmetro, os resultados da análise de variância não apresentaram, na primeira avaliação, realizada após 14 dias de armazenamento, efeito significativo para nenhum dos fatores (Tabela 1). Independentemente das doses e das épocas de cultivo, a média de nota foi de 4,25 apresentando cabeças comerciais levemente deterioradas. Estes resultados são semelhantes aos observados por Resende et al. (2005) que, em avaliação da qualidade pós-colheita de alface americana em função de doses de nitrogênio e molibdênio, obtiveram nota média próxima de 4,0 após um período de 14 dias de armazenamento em câmara fria.

Pela análise de variância da qualidade pós-colheita de cabeças de alface-americana após 21 dias de armazenamento, pode-se observar que houve diferença significativa entre os tratamentos, de modo isolado, apenas para o fator doses de N. Para essa característica, o melhor ajuste foi verificado pela equação de primeiro grau negativo, ou seja, à medida que se aumentou a dose de nitrogênio, houve uma redução na qualidade das cabeças de alface-americana. $\mathrm{Na}$ menor dose, a média de nota observada foi de 3,50, enquanto que na maior dose, a nota decresceu para uma média de 2,33 (Figura 
YURI, J. E. et al.

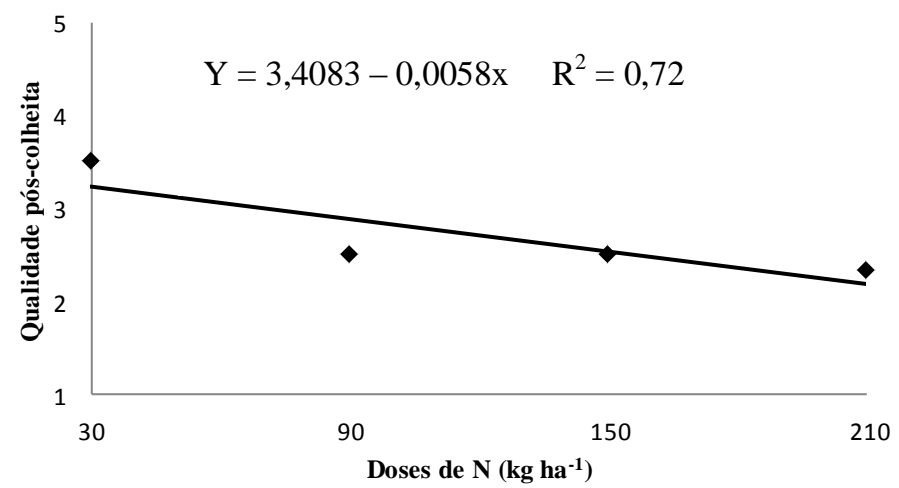

Figura 2. Escala de notas referentes à qualidade pós-colheita (21 dias) em função de doses de nitrogênio.

Os resultados obtidos corroboram com Hoque et al. (2010) que descrevem as influências negativas do excesso de

\section{CONCLUSÕES}

Nas condições do município de Três Pontas-MG, a recomendação para o cultivo de verão é a utilização de $30 \mathrm{~kg} \mathrm{ha}^{-1}$ de $\mathrm{N}$ em adubação de cobertura, desde que associada a mais $30 \mathrm{~kg} \mathrm{ha}^{-1}$, totalizando 60

\section{REFERÊNCIAS}

ARAÚJO, S. T.; FIDELES FILHO, J.; KUMAR, K. K.; RAO, T. V. R. Crescimento da alface americana em função dos ambientes, épocas e graus dias.

\section{Revista Brasileira de Ciências Agrárias,} v. 5, n. 4, p. 441-449, 2010.

BASTOS, E.A.; CARDOSO, M.J.; MELO, F.B.; RIBEIRO, nitrogênio na qualidade pós-colheita da alface, favorecendo o aumento da concentração de nitratos.

$\mathrm{kg} \mathrm{ha}{ }^{-1}$, que proporcionará melhor rendimento produtivo e, também, qualidade pós-colheita, favorecendo maior tempo de prateleira. Para o inverno, na mesma região, o total recomendado é de $125 \mathrm{~kg} \mathrm{ha}^{-1}$ de $\mathrm{N}$.

ANDRADEJÚNIOR, A.S. Doses e formas de parcelamento de nitrogêniopara a produção de milho sob plantio direto. Revista Ciência Agronômica, v.39, n.2, p.275-280, 2008.

BERNARDI, A. C. C.; VERRUMABERNARDI, M. R.; WERNECK, C. G.; HAIM, P. G.; MONTE, M. B. M. 
Produção, aparência e teores de nitrogênio, fósforo e potássio em alface cultivada em substrato com zeólita. Horticultura Brasileira, v. 23, n. 4, p. 920-924, 2005.

DECOTEAU D. R.; RANWALA, D.; McMAHON M. J.; WILSON, S. B. The lettuce growing handbook: botany, field procedures, growing problems, and postharvest handling. Illinois: Oak Brook, 1995. $60 \mathrm{p}$.

EMPRESA BRASILEIRA DE PESQUISA AGROPECUÁRIA - EMBRAPA. Sistema brasileiro de classificação de solos. 3 ed. Brasília, 2013. 353p.

EPSTEIN, E.; BLOOM, J. A. Nutrição mineral de plantas: princípios e perspectivas. Londrina: Editora Planta, 2004.402p.

FELTRIM, A. L.; CECÍlio FILHO, A. B.; BRANCO, R. B. F.; BARBOSA, J. C.; SALATIEL, L. T. Produção de alface americana em solo e em hidroponia, no inverno e verão, em Jaboticabal, SP. Revista Brasileira de Engenharia Agrícola e Ambiental, v. 9, n. 4, p. 505509, 2005.

HOQUE, M. M.; AJWA, H.; OTHMAN, M. Yield and postharvest quality of lettuce in response to nitrogen, phosphorus, and potassium fertilizers. Hortscience, v. 45, n. 10, p. 1539-1544, 2010.

MANTOVANI, J. R.; FERREIRA, M. E.; CRUZ, M. C. P. Produção da alface e acúmulo de nitrato em função da adubação nitrogenada. Horticultura Brasileira, v. 23, n. 3, p. 758-762, 2005.

RESENDE, G.M.; ALVARENGA, M.A.R.; YURI, J.E.; MOTA, J. H.; SOUZA, J.R.; RODRIGUES JÚNIOR, J.C. Produtividade e qualidade pós-colheita da alface americana em função de doses de nitrogênio e molibdênio. Horticultura Brasileira, v. 23, n. 4, p. 976-981, 2005.

RESENDE, G. M.; ALVARENGA, M. A. R.; YURI, J. E.; SOUZA, J. R. Rendimento e teores de macronutrientes em alface americana em função de doses de nitrogênio e molibdênio. Horticultura Brasileira, v. 30, n. 3, p. 373-378, 2012.

SILVA, P. A. M.; PEREIRA, G. M.; REIS, R. P.; LIMA, L. A.; TAVEIRA, J. H. S. Função de resposta da alface americana aos níveis de água e adubação nitrogenada. Ciência e Agrotecnologia, v. 32, n. 4, p. 1266-1271, 2008.

SOUZA, A. L.; SEABRA, J. S.; SILVIA, D. M.; CAMPOS DE SOUZA, L. H.; MOITINHO N. M. C. Comportamento de 
cultivares de alface americana sob clima tropical. Revista Caatinga, v. 26, n. 4, p. 123-129, 2013.

TRANI, P. E.; RAIJ, B. Hortaliças. In: RAIJ, B.; CANTARELLA, H.; QUAGgiO, J. A.; FURLANI, A. M. C. (Eds). Recomendações de adubação e calagem para o Estado de São Paulo. 2 ed. Campinas: Instituto Agronômico/Fundação IAC, (Boletim Técnico, 100), cap. 18, 1997. p. 157-185.
TRANI, P. E.; RAIJ, B. van. Hortaliças. In: RAIJ, B. van; CANTARELLA, H.; QUAGGIO, J. A.; FURLANI, A. M. C. (Eds.) Recomendações de adubação e calagem para o Estado de São Paulo. 2 ed. Campinas: Instituto Agronômico/Fundação IAC, 1997. p.157164. (Boletim Técnico, 100)

YURI, J. E.; SOUZA, R. J.; FREITAS, S. A. C.; RODRIGUES JÚNIOR, J. C.; MOTA, J. H. Comportamento de cultivares de alface tipo americana em Boa Esperança. Horticultura Brasileira, v. 20, n. 2, p. 229-232, 2002. 